\title{
Wind Farms Fault Ride Through using DFIG with New Protection Scheme
}

\author{
Kenneth E. Okedu, Student Member, IEEE, S.M. Muyeen, Member, IEEE, Rion Takahashi, Member \\ IEEE, and Junji Tamura, Senior Member, IEEE
}

\begin{abstract}
This paper proposes a control strategy of doubly fed induction generators (DFIGs) with new protection schemes for enhancing fault ride through capability of wind farms composed of DFIGs and induction generators (IGs). Since the DFIGs will be stressed or overloaded in the process of stabilizing the wind farm during a grid fault, it is paramount to consider a protection scheme for the DFIG, in order to protect its power converters. Two schemes, the DC-link chopper-controlled braking resistor with the supplementary rotor current (SRC) control of the rotor side converter of the DFIG and series dynamic braking resistor (SDBR) connected to the stator of the DFIG, are proposed and compared. Merits and drawbacks of both schemes are highlighted as well. The simulation results in PSCAD/EMTDC show that the two proposed schemes can eliminate the need for an expensive crowbar switch in the rotor circuit, because both could limit the rotor current of the DFIG within its nominal value during a grid fault. Finally, considering the overall system performance, the latter is recommended.
\end{abstract}

Index Terms - Doubly fed induction generator (DFIG), Series dynamic braking resistor (SDBR), Wind energy, Wind farms, Stability, Protection schemes, Induction generator.

\section{INTRODUCTION}

$\mathrm{T}$ HE most demanding requisite for wind farms, especially with doubly fed induction generators (DFIG), which is used as a variable speed wind turbine (VSWT) generator, is the fault ride through (FRT) capability. Wind farms connected to high voltage transmission system must remain connected when voltage dip occurs in the grid, otherwise, the sudden disconnection of a great amount of wind power may contribute to the voltage dip, with terrible consequences [1-3]. FRT is required to be considered nowadays for connection of large wind farms to most power systems. The FRT refers to the capability of generation plant to remain connected with being dynamically stable, and offer network support throughout a serious voltage disturbance on the transmission network. The FRT compliant wind farm must remain connected to the power system and actively contribute to the system stability during a wide range of network fault scenarios [4].

Many methods have been proposed to improve the FRT of

Manuscript received February 14, 2011; revised September 25, 2011.

Kenneth E. Okedu, Rion Takahashi, and Junji Tamura, are with the Electrical and Electronic Engineering Department, Kitami Institute of Technology, Hokkaido, 090-8507 Japan (corresponding author e-mail: kenokedu@yahoo.com or dse09801@ std.kitami-it.ac.jp)

S. M. Muyeen is with the Electrical Engineering Department, The Petroleum Institute, Abu Dhabi, U.A.E fixed speed wind farms, since the fixed speed wind turbine (FSWT) generator, for which an induction generator (IG) is mostly used, requires large reactive power to recover the air gap flux and has the limited ability to provide voltage control when a short circuit fault occurs in the power system. Hence, the installation of expensive external reactive power compensation devices is needed. Static synchronous compensators (STATCOM), superconducting magnetic energy storage (SMES) system and energy capacitors (ECS), which are flexible ac transmission system (FACTS) devices, have been proposed so far [5-7] for the reactive power compensation in stabilizing the fixed speed wind farms. This study focuses on stabilizing FSWT without using any FACTS device.

The DFIG is a popular wind power generator because of its variable wind speed tracking performance and relatively low cost due to the use of partially rated power converter compared to permanent magnet synchronous generator (PMSG) with fully rated converter. However, during a grid fault, the DFIG is vulnerable to grid disturbances because the stator windings are connected directly to the grid while the rotor windings are buffered from the grid via a partially-rated frequency converter [8-11]. In [4, 12], a crowbar was used to improve the FRT of DFIG, while in $[13,14]$, a DC-chopper was used. The strategy of combining the crowbar system and the DC-chopper system was previously studied in [15], while a comparative study of both protection systems was reported in [16]. A static series compensator (SSC) or a dynamic voltage restorer (DVR) [17-19] and STATCOM [20] were used to improve the FRT of the DFIG. A series dynamic braking resistor (SDBR) was used to improve the FRT of large wind farms composed of induction generators in [21], while in [22] the SDBR was connected to the rotor side converter of the DFIG to improve its FRT. Superconducting fault current limiter (SFCL) [23], passive resistance network [24], and series antiparellel thyristors [25] connected to the stator side of a grid connected DFIG, have also been proposed in the literature.

A small size SBDR can be inserted in series with the stator circuit of the DFIG through the control of power electronic switches to balance the active power, which eventually improves the wind generator stability during a grid fault and is less expensive than the SFCL, passive resistance network and series antiparallel thyristor. This study deals with two protection schemes, which are relevant to the rotor current and DC-link voltage of the DFIG; crowbar and DC-link chopper. Two schemes, which work in combination with the DC-link chopper and braking resistor, are proposed to limit the rotor current of the DFIG during a grid fault; that is, the coordinated 
control of the $\mathrm{d}$ and $\mathrm{q}$ axis rotor currents in the rotor side converter of the DFIG based on a supplementary rotor current controller (scheme 1), and the use of small value of series dynamic braking resistor (SDBR) connected to the stator of the DFIG (scheme 2). Though both schemes can limit the rotor current of the DFIG during a grid fault, scheme 1 is cheaper but it can only limit the rotor current, while scheme 2 can also stabilize the DC-link voltage and other variables of the DFIG, like the rotor speed, terminal voltage, etc. In Scheme 2, the effect of the magnitude of the SDBR is also investigated along its insertion time and duration of operation. The simulation results show that the smaller SDBR value gives better performance in stabilizing the DFIG, and hence the small value is used to determine the best insertion time of the SDBR. The shorter duration of operation of the SDBR gives a better response of the DFIG system during a grid fault. This work attempts to improve further the overall performance of DFIG during a grid disturbance. Hence, a new control strategy using a DC-chopper inserted into the DC-link circuit of the DFIG and a small value of SDBR connected in series in the stator of the DFIG, is proposed, the former of which acts as a damping load to suppress the DC-link voltage during a grid fault. Another salient feature of this study is the application of the proposed strategy to a multi-machine system including wind farms, in which the wind farms composed of fixed and variable speed wind generators can be stabilized without using STATCOM or other energy storage systems. In addition, the two-mass drive train model is used in the analysis for all wind generators because the drive train modeling has great influence on the transient stability. Simulations were run in PSCAD/EMTDC [26].

\section{WIND TURBINE MODELING}

The primary components in modeling of a wind turbine system consist of the turbine rotor or prime mover, a shaft and a gearbox unit. The aerodynamic torque and the mechanical power of a wind turbine are given by $[14,27]$ :

$$
\begin{aligned}
T_{M} & =0.5 \rho C_{t}(\lambda) \pi R^{3} V_{w}^{2}[\mathrm{NM}] \\
P_{w t} & =0.5 \rho C_{p}(\lambda, \beta) \pi R^{2} V_{w}^{3}[W]
\end{aligned}
$$

Where $\rho$ is the air density, $\mathrm{R}$ is the radius of the turbine, $V_{w}$ is the wind speed, $C_{p}(\lambda, \beta)$ is the power coefficient given by

$$
C_{p}(\lambda, \beta)=0.5\left(\Gamma-0.02 \beta^{2}-5.6\right) e^{-0.17 \Gamma}
$$

The relationship between $C_{t}$ and $C_{p}$ is

$$
\begin{gathered}
C_{t}(\lambda)=\frac{C_{p}(\lambda)}{\lambda} \\
\lambda=\frac{\omega_{w t} R}{V_{w}} \\
\Gamma=\frac{R(3600)}{\lambda(1609)}
\end{gathered}
$$

The rotational speed $[\mathrm{rad} / \mathrm{s}]$ of the wind turbine is $\omega_{w t}$, the tip speed ratio is $\lambda$ and $C_{p}$ is the power coefficient. Figures 1 and 2 show the wind turbine characteristics [28] used in this study for IG (FSWT) and DFIG (VSWT) respectively.

Equations (7) to (9) are used to determine the active power output reference $P_{\text {ref }}$ and the optimal wind turbine speed $\omega_{w t_{-} o p t}$ as a function of wind speed for maximum power point tracking (MPPT) control. The operating range for the turbine speed is chosen between $0.7 \mathrm{pu}$ (minimum) to $1.3 \mathrm{pu}$ (maximum) as shown in the wind turbine characteristics in Fig.2. Figure 3 shows the control block for generating $P_{\text {ref }}$.

$$
\begin{aligned}
P_{\text {ref } 1}=0.1571 V_{w}-1.035 & {[\mathrm{pu}] } \\
P_{\text {ref } 2}=0.2147 V_{w}-1.668 & {[\mathrm{pu}] } \\
\omega_{\text {ropt }}=0.0775 V_{w} & {[\mathrm{pu}] }
\end{aligned}
$$

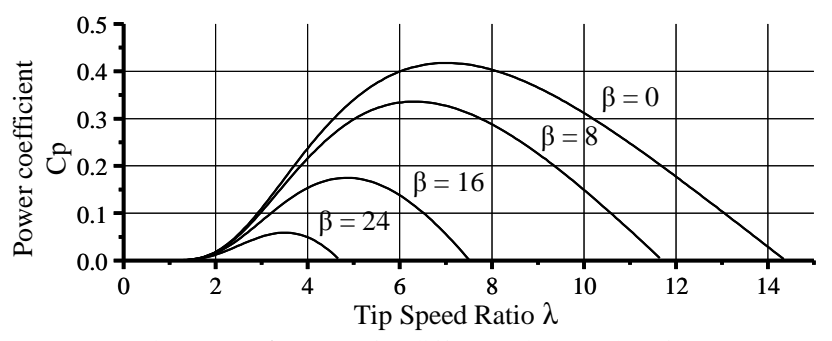

Fig. $1 . \mathrm{C}_{\mathrm{P}^{-}} \lambda$ curves for different pitch angles (for FSWT)

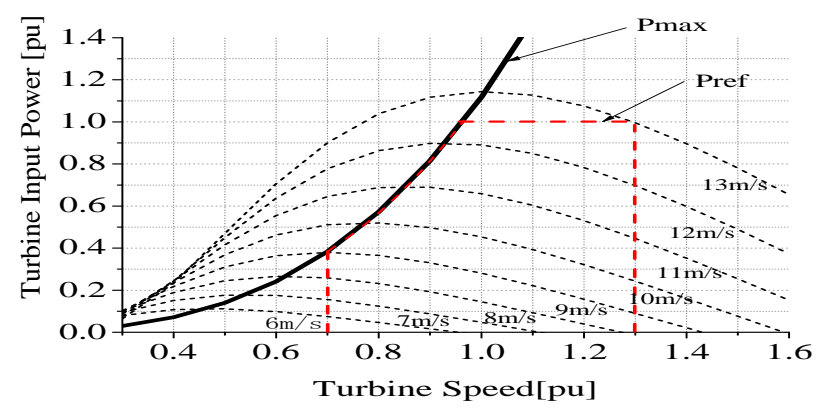

Fig. 2. Turbine characteristic with maximum power point tracking (for VSWT)

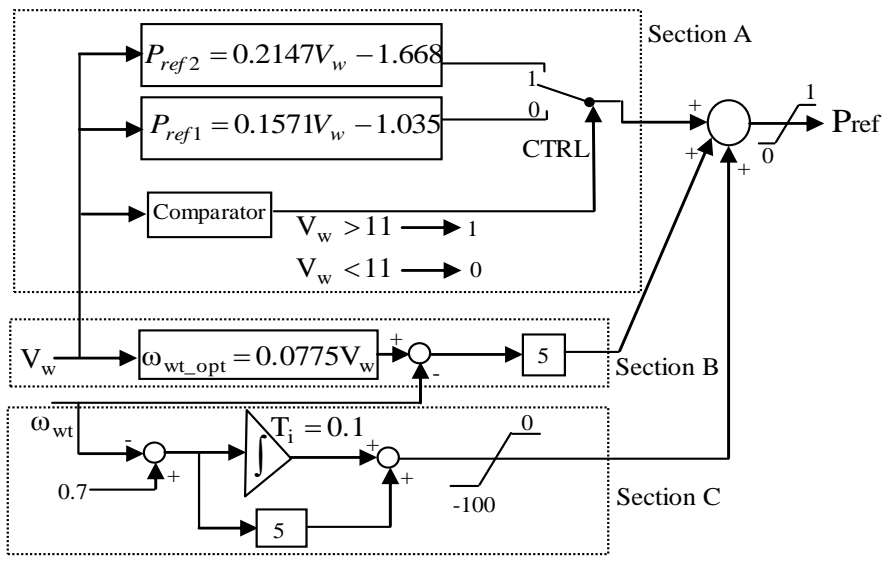

Fig. 3. Control block to determine active power reference $P_{\text {ref }}$

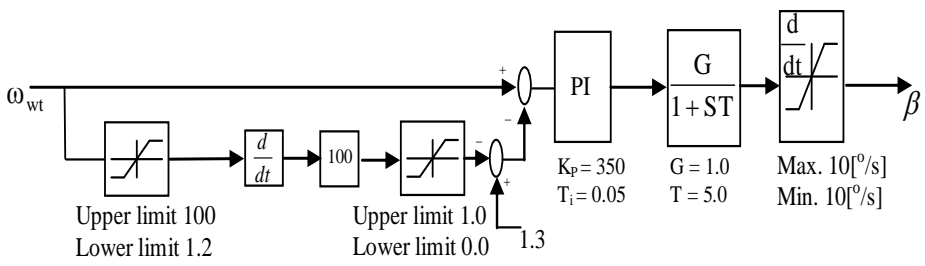

Fig. 4. Pitch controller for VSWT 


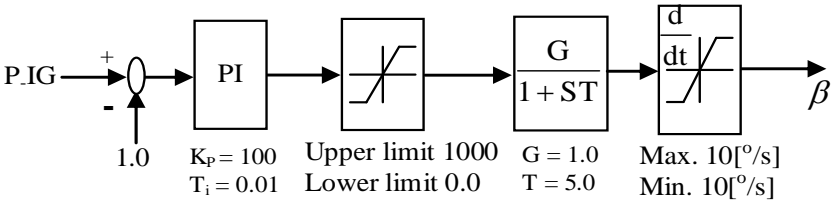

Fig. 5. Pitch controller for FSWT

Figures 4 and 5 shows the pitch angle controllers used in this study for the VSWT and the FSWT respectively.

\section{Conventional Protection SChemes of DFIG}

Figure 6 shows a model system with the crowbar and the DC-link chopper protection schemes. Though both schemes are included together in the figure as DFIG protection scheme $[2,4$, 12 , and 16], the cost of the crowbar scheme is relatively high and it also requires the disconnection of the rotor side converter of the DFIG during a grid fault. Thus, this study proposes an alternative scheme which uses the DC-link chopper protection scheme. In the following subsections both schemes are described in the light of Fig. 6.

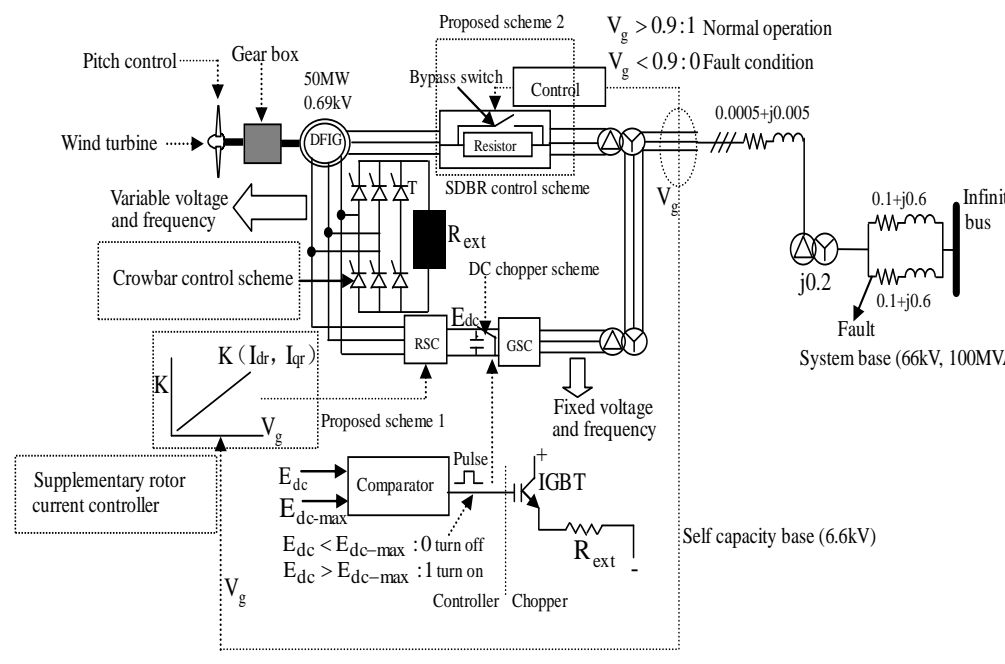

Fig. 6. Model system with protection schemes

\section{A. Crowbar Protection Scheme}

For protecting the converters, a crowbar is connected between the rotor and the rotor-side converter as shown in Fig.6 $[29,30]$. The crowbar system used in modern wind turbines is based on a three-phase series resistance controlled by power electronics devices. The crowbar system is activated during over-current on the rotor windings or over-voltage on the DC link, which can appear after a short circuit fault close to the wind farm. In this study the pulse signal to trigger the crowbar is given when the DC-link voltage $\mathrm{E}_{\mathrm{dc}}$ exceeds $\mathrm{E}_{\mathrm{dc}-\max }$. The excitation parameters are given in Table I [14]. The steps involved during the activation and deactivation of the crowbar system are; disconnection of the rotor windings from the rotor side converter (RSC), insertion of the three-phase resistance in series to the rotor windings, disconnection of the crowbar system from the rotor windings, and reconnection of the RSC to the rotor windings. These actions will help to prevent the high rotor currents and excessive DC-link voltage. Amplitude of the resulting voltage in the rotor circuit is determined by the crowbar resistors. The crowbar resistor also acts as an active power sink, consuming active power to mitigate rotor over-speeding. During the time the crowbar is activated, the generator works as a conventional induction generator with high rotor resistance. Several different chains of events can follow a crowbar action, and these are effectively the different low voltage ride through (LVRT) strategies. One possibility is to overrate the IGBT modules in the converter to allow for high voltage tolerance of the DC-link, the second is to disconnect the rotor side converter with the grid side converter connected, and the third is to disconnect the stator from the grid but continue the active operation of both converters and the DC-link. The main goal of the LVRT system is to resume active operation of the wind turbine after a grid fault clearance.

\section{B. DC-link Voltage Protection Scheme}

A chopper circuit with a resistance can be added to the DC-link as shown in Fig. 6 with a similar function to that of the rotor side crowbar in order to reduce the DC-link voltage $[14,16]$. The chopper facilitates a voltage-raising action from the converter terminals, enabling a fast recovery of the DC-link voltage. The protective device in this scheme is a simple chopper circuit and a resistance. The pulse signal to trigger the IGBT is activated when $E_{\mathrm{dc}}$ exceeds $\mathrm{E}_{\mathrm{dc}-\max }$, and thus, the chopper is turned on and the energy is dissipated by the internal resistance. The value of $\mathrm{E}_{\mathrm{dc}-\max }$ and other parameters of protection circuit used in this study are shown in Table I.

TABLE I

RATINGS AND PARAMETERS OF EXCITATION CIRCUIT

\begin{tabular}{|c|c|}
\hline DC link voltage & $1.5 \mathrm{kV}$ \\
\hline DC link capacitor & $50,000 \mu \mathrm{F}$ \\
\hline Device for power converter & IGBT \\
\hline PWM carrier frequency & $2 \mathrm{kHz}$ \\
\hline $\begin{array}{l}\text { Upper limit of DC voltage } \\
\left(\mathrm{E}_{\mathrm{dc} \_ \text {Max }}\right)\end{array}$ & $1.65 \mathrm{kV}(110 \%)$ \\
\hline $\begin{array}{l}\text { Lower limit of DC voltage } \\
\left(\mathrm{E}_{\mathrm{dc} \_ \text {Min }}\right)\end{array}$ & $0.75 \mathrm{kV}(50 \%)$ \\
\hline $\begin{array}{l}\text { Short circuit parameter of } \\
\text { protective device for over voltage }\end{array}$ & $0.2 \mathrm{ohm}$ \\
\hline
\end{tabular}

\section{Proposed Protection Scheme of DFIG}

Two schemes to limit the rotor current of the DFIG during a grid fault, which work cooperatively with the DC-link chopper, are proposed. The first scheme is based on the coordinated control of the $\mathrm{d}$ and $\mathrm{q}$ axis rotor currents in the RSC of the DFIG with using a supplementary rotor current (SRC) controller [31, 32]. A small value $(0.1 \mathrm{pu})$ of series dynamic braking resistor (SDBR) connected to the stator of the DFIG is used in the second scheme [33, 34]. The mathematical expression for the effect of grid fault on the DFIG rotor currents is given in the Appendix.

\section{A. Supplementary Rotor Current (SRC) Control and DC Chopper Scheme}

A new control strategy in the RSC shown in Fig.7 is proposed. 
When a grid fault occurs, if $\operatorname{Vg}<0.9$, then the comparator sends a signal to switch the obtained currents Idr and Iqr to be multiplied by a variable $\mathrm{K}$ determined by the look up table (in supplementary rotor current controller) as shown in Fig. 7. The variable $\mathrm{K}$ is directly proportional to the magnitude of the grid voltage $\mathrm{Vg}$ during the grid fault.

The process of multiplying $\mathrm{K}$ to the $\mathrm{d}$ and $\mathrm{q}$ rotor currents during a grid fault helps to limit the magnitude of the rotor current of the DFIG within its nominal value. Hence the use of expensive crowbar switch to disconnect the RSC from the DFIG during the grid fault can be avoided, since the recent grid codes require all wind turbine generators to remain connected to the power network during and after a grid fault. The DC chopper helps to protect the DC-link circuit.

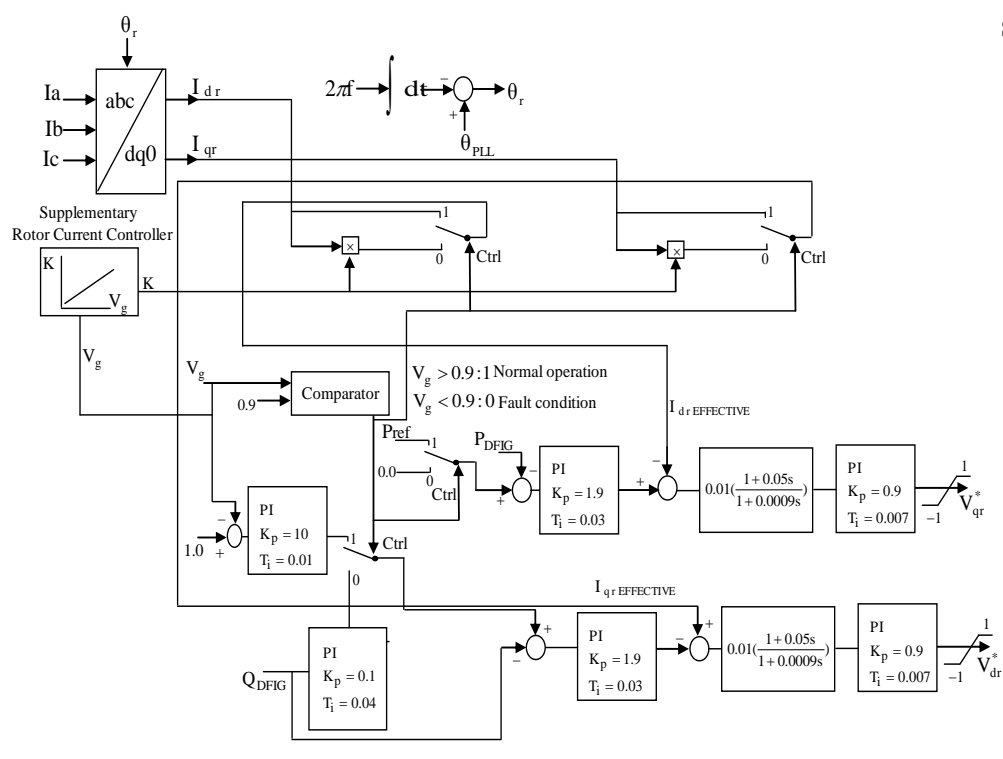

Fig. 7. Control block for rotor side converter of DFIG with Idr and Iqr control

\section{B. Series Dynamic Braking Resistor Control at DFIG Stator Circuit and DC-Chopper Scheme.}

A small value of series dynamic braking resistor connected to the stator of the DFIG (Fig. 6), instead of the rotor, incorporated with the DC-link protection scheme is proposed in this paper. This combination helps to improve further the overall performance of the DFIG during a grid fault. In normal operation, the switch is on and the resistor is bypassed, but the switch is off and the resistor is connected in series to the stator circuit during fault condition.

The difference between the SDBR and the crowbar or DC-link chopper/braking resistor is their topology. The latter is shunt-connected and the voltage is controlled by it, while the SDBR has the advantage of controlling the current magnitude. Also, in the SDBR strategy, the high voltage will be shared by the resistance because of the series topology. Therefore, the induced overvoltage may not lead to the loss of converter control. The SDBR not only control the rotor overvoltage which could cause the RSC to lose control, but limits high rotor current more significantly. In addition, the rotor current limitation can also reduce the charging current to the DC-link capacitor, hence avoiding DC-link overvoltage which could damage the DFIG power converter. The SBDR can also balance the active power of the DFIG, and thus, can also improve the DFIG wind generator stability during a fault. Also, the SDBR will increase the generator output and therefore reduce its speed increase during a voltage dip. This effect would improve the post fault recovery of the DFIG system and the entire wind farm, because the SDBR controls and improves the rotor speed acceleration during a grid fault.

\section{BENEFIT OF CONNECTING SDBR AT THE STATOR SIDE OF DFIG}

The distinctive merit of series dynamic braking resistor is based on the fact that its effect is related to current magnitude rather than voltage magnitude. The benefit of connecting the SDBR at the stator side instead of the rotor side of a DFIG is shown schematically in Fig. 8 based on [21].

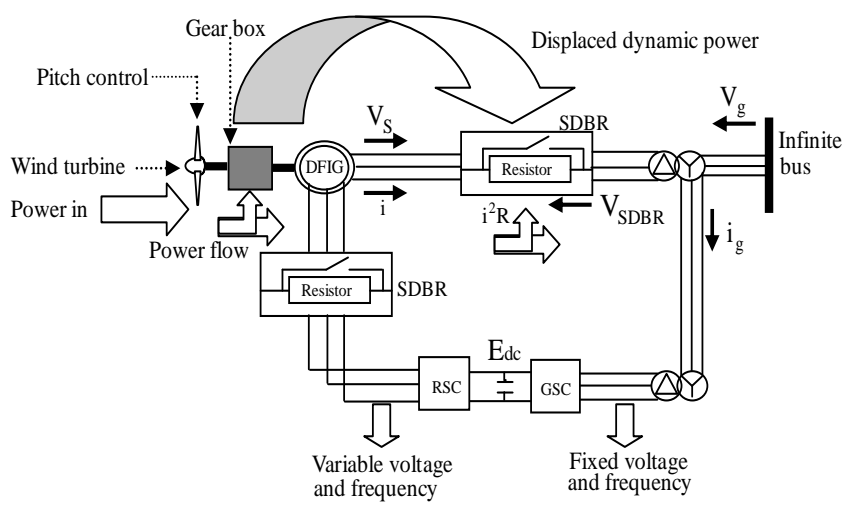

Fig. 8. Merit of connecting SDBR at the stator of DFIG

In Fig. 8, the generated power is transferred across the wind generator system, while the excess dynamic power is stored in its drive train and heat is dissipated by the SDBR. Fig. 9 shows the phasor diagram in the case with SDBR connected.

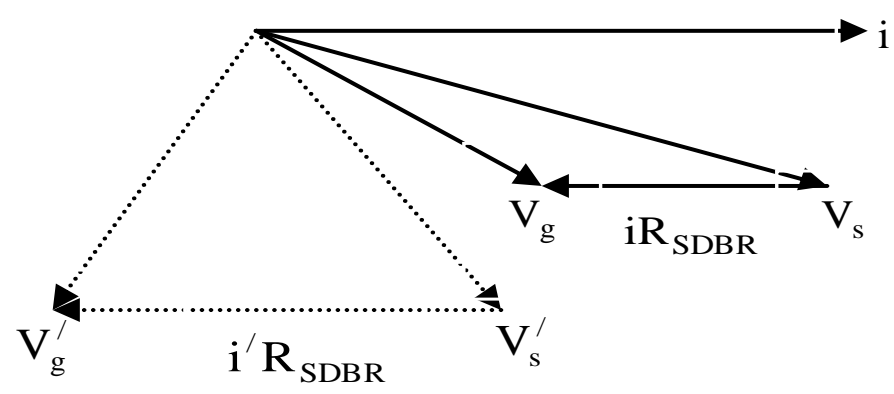

Fig. 9. Effect of SDBR on stator voltage of DFIG

From Fig. 9, the voltage across the SDBR is $i_{\mathrm{SDBR}}$, and the stator voltage $\left(\mathrm{V}_{\mathrm{s}}\right)$ is increased by the voltage across the SDBR during grid fault. This is because, when the SDBR is connected to the stator of the DFIG, it will increase the mechanical power extracted from the drive train, thus reducing its speed excursion. Also, since mechanical torque is proportional to the square of the stator voltage of the DFIG, the effect would enhance the post fault recovery of the DFIG. The limiting beneficial case at very low power factor when SDBR has no effect on the stator voltage magnitude is shown also in Fig. 9 with the dotted phasor lines. The effect of connecting the SDBR at the stator 
instead of the rotor of the DFIG is shown in the simulation results in section IX for both cases during grid fault.

\section{OVERALl CONTROL STRATEGY OF DFIG CONSIDERING SDBR}

The control block of the DFIG rotor side converter (RSC), the grid-side converter (GSC), and the SDBR control system is shown in Fig. 10.

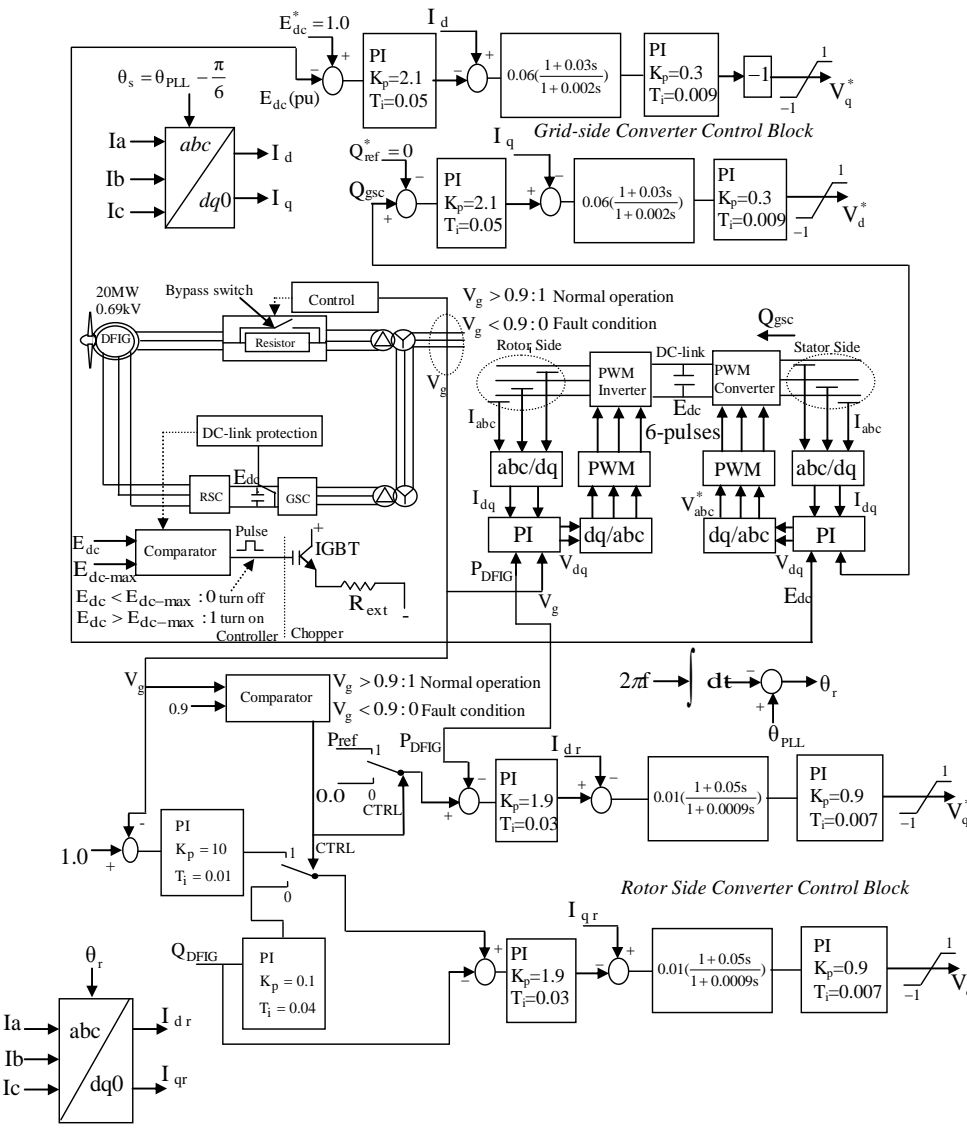

Fig. 10. Control block of DFIG and SDBR

The power converters are usually controlled utilizing vector control techniques. The DFIG control described in Fig. 10 contains the electrical control of the power converters, which is essential for the DFIG behavior both in normal operation and during fault condition.

In Fig. 10, the rotor side converter controls the terminal (grid) voltage to 1.0pu. The d-axis current controls the active power, while the q-axis current controls the reactive power. After dq0-to-abc transformation, $V_{d r}^{*}$ and $V_{q r}^{*}$ are sent to the PWM signal generator and $V_{a b c}^{*}$ are the three-phase voltages reference for the rotor side converter as shown in the converter configuration circuit.

Also in Fig. 10, the control block for the GSC control is shown, where PLL provides the angle $\theta_{P L L}$ and $\theta_{s}$ is the effective angle for the abc-to-dq0 (and dq0-to-abc) transformation. The GSC of the DFIG system is used to regulate the DC-link voltage $\left(E_{d c}\right)$ to $1.0 \mathrm{pu}$. The d-axis current controls the DC-link voltage, while the q-axis current controls the reactive power of the grid side converter. After a dq0- to-abc transformation, $V_{q}^{*}$ and $V_{d}^{*}$ are sent to the PWM signal generator. Finally, $V_{a b c}^{*}$, voltage reference, are sent to the GSC for the IGBT's switching.

As shown in Fig. 10, both the RSC and GSC are controlled by a two-stage controller. The first stage consists of very fast current controllers regulating the rotor currents to their reference values, and the second stage consists of slower power controllers.

The SDBR control is done by inserting a resistor in the stator of the DFIG during a fault, and thus, the terminal voltage of the generator increases, mitigating the destabilizing depression of electrical torque and power. The schematic arrangement and control strategy is shown in Fig. 10. Either a bypass switch or a circuit breaker could be used for the SDBR control strategy. But the cost of a bypass switch is less expensive than that of a circuit breaker. The bypass switch for the SDBR is normally on, but when voltage dip below 0.9 pu occurs due to a grid fault, it opens to allow current pass through a small series resistance. Current then begins to flow through the inserted resistor. When voltage is recovered above a certain specified level, the bypass switch closes and the stator circuit restores to its normal state. During the short insertion period, the energy is dissipated in the resistor, raising its temperature. The resistor should be selected according to its temperature limit and the maximum energy which can be dissipated during the short period.

\section{EFFECT OF THE MAGNITUDE AND THE SWITCHING TIME OF SDBR}

During a grid fault, the SDBR mitigates acceleration of wind generators more strongly. This effect is a result of the additional power, some of which is exported into the grid and the remainder is dissipated in the SDBR resistor [22]. The energy dissipated by SDBR determines its size and cost. This energy can be optimized by changing the switch-out time. The switch-in time, on the other hand, should be as short as possible to maximize its speed limitation effect. Two control strategies by using a bypass switch and a circuit breaker are investigated to show the effect of the SDBR magnitude, along its insertion time and duration of operation, on the stability of the wind generator. Different values of SDBR resistance, $0.05 \mathrm{pu}, 0.1 \mathrm{pu}$ and $0.15 \mathrm{pu}$, are used in the analysis which will be shown in the simulation results. According to the simulation results, the small SDBR resistance of $0.05 \mathrm{pu}$ gives a better response. Hence this value is used to investigate the insertion time and duration of operation of the SDBR, as summarized in Table II.

Table II

Considered cases of SDBR switching time

\begin{tabular}{|c|c|c|}
\hline Switch-in time(ms) & Switch-out time(ms) & $\begin{array}{c}\text { Duration of } \\
\text { operation(ms) }\end{array}$ \\
\hline 120 & 200 & 80 \\
\hline 150 & 250 & 100 \\
\hline 180 & 300 & 120 \\
\hline
\end{tabular}

(Note) Fault occurs at $100 \mathrm{~ms}$.

As will be shown in the simulation results in section IX, the quicker the insertion time of the SDBR and the shorter its 
duration of operation, the better the stability performance of the DFIG during a grid fault.

\section{MODEL SYSTEM}

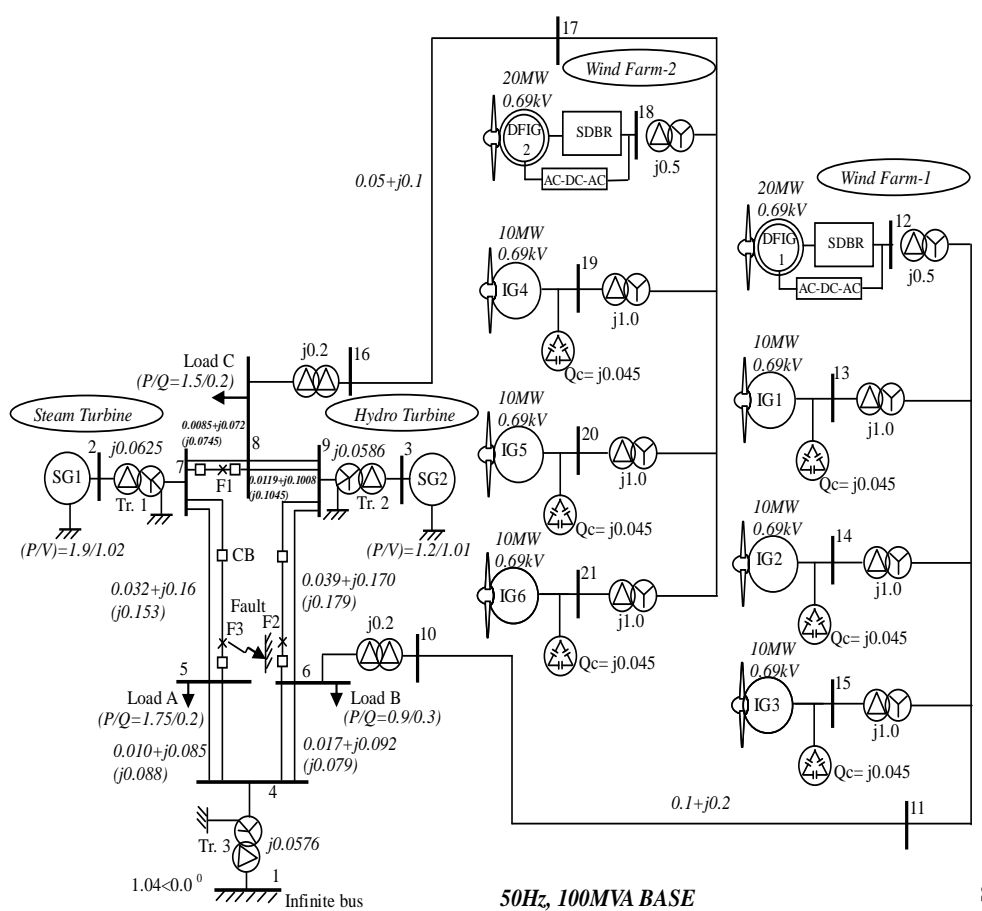

Fig. 11. Multi-machine model system

A model system shown in Fig. 11 [35], where two wind farms are connected to the multi-machine power system, is used in the simulation analyses in which the proposed DFIG and SDBR (0.05pu) control strategies are considered. Aggregated wind farm model is considered in this analysis. Each wind farm is composed of 1 DFIG and 3 IGs. The parameters of the generators are given in Table III, in which a double-cage rotor type model is used for IG. The two-mass shaft model is considered as well for all wind turbine generator systems, because the shaft modeling has great influence on the fault analysis. The two-mass drive train parameters of wind generators are shown in Table III, where $H_{g}$ and $H_{w t}$ are the generator and wind turbine inertia constants respectively, and $K_{w}$ is the shaft stiffness between the two masses.

The IEEE generic turbine model and approximate mechanical-hydraulic speed governing system [36] is used for synchronous generator 1 (SG1). The IEEE "non-elastic water column without surge tank" turbine model and "PID control including pilot and servo dynamics" speed-governing system [37] is used for synchronous generator 2 (SG2). IEEE alternator supplied rectifier excitation system (ACIA) [38] is used in the exciter model of both synchronous generators.
TABLE III

GENERATOR PARAMETERS

\begin{tabular}{|c|c|c|c|c|c|}
\hline $\begin{array}{c}\text { Generator } \\
\text { Type }\end{array}$ & SG1 & SG2 & $\begin{array}{c}\text { Generator } \\
\text { Type }\end{array}$ & IGs & DFIGs \\
\hline MVA & 200 & 130 & MVA & 10 & 20 \\
\hline $\mathrm{r}_{\mathrm{a}}(\mathrm{pu})$ & 0.003 & 0.003 & $\mathrm{r} 1(\mathrm{pu})$ & 0.01 & 0.01 \\
\hline $\mathrm{X}_{\mathrm{a}}(\mathrm{pu})$ & 0.102 & 0.130 & $\mathrm{x} 1(\mathrm{pu})$ & 0.1 & 0.15 \\
\hline $\mathrm{X}_{\mathrm{d}}(\mathrm{pu})$ & 1.651 & 1.200 & $\mathrm{Xmu}(\mathrm{pu})$ & 3.5 & 3.5 \\
\hline $\mathrm{X}_{\mathrm{q}}(\mathrm{pu})$ & 1.590 & 0.700 & $\mathrm{r} 21(\mathrm{pu})$ & 0.035 & 0.01 \\
\hline $\mathrm{X}_{\mathrm{d}}^{\prime}(\mathrm{pu})$ & 0.232 & 0.300 & $\mathrm{x} 21(\mathrm{pu})$ & 0.030 & 0.15 \\
\hline $\mathrm{X}_{\mathrm{q}}^{\prime}(\mathrm{pu})$ & 0.380 & & $\mathrm{r} 22(\mathrm{pu})$ & 0.014 & \\
\hline $\mathrm{X}_{\mathrm{d}}^{\prime \prime}(\mathrm{pu})$ & 0.171 & 0.220 & $\mathrm{x} 22(\mathrm{pu})$ & 0.098 & \\
\hline $\mathrm{X}_{\mathrm{q}}^{\prime \prime}(\mathrm{pu})$ & 0.171 & 0.250 & $\mathrm{Hg}(\mathrm{pu})$ & 0.3 & 0.3 \\
\hline $\mathrm{T}^{\prime}{ }_{\mathrm{do}}(\mathrm{sec})$ & 5.900 & 5.000 & $\mathrm{Hwt}(\mathrm{pu})$ & 3.0 & 3.0 \\
\hline $\mathrm{T}^{\prime}{ }^{\prime} \mathrm{qo}(\mathrm{sec})$ & 0.535 & & $\mathrm{Kw}(\mathrm{pu})$ & 90 & 90 \\
\hline $\mathrm{T}^{\prime \prime} \mathrm{do}(\mathrm{sec})$ & 0.033 & 0.040 & & & \\
\hline $\mathrm{T}^{\prime \prime} \mathrm{qo}(\mathrm{sec})$ & 0.078 & 0.050 & & & \\
\hline $\mathrm{H}^{(\mathrm{sec})}$ & 9.000 & 2.500 & & & \\
\hline
\end{tabular}

\section{Simulation Results AND Discussions}

\section{A. Analysis using Simple Model:}

Simulation analyses for a three-line-to-ground (3LG) fault, as shown in Fig. 6, are performed using the model system in section III. The DFIG is operating at the rated power under $15 \mathrm{~m} / \mathrm{s}$ wind speed in this case. Simulations are carried out using PSCAD/EMTDC. A $100 \mathrm{~ms}$ fault is considered to occur at $0.1 \mathrm{sec}$. The circuit breakers on the faulted line are opened and reclosed at $0.2 \mathrm{sec}$ and $1.0 \mathrm{sec}$ respectively. A supplementary rotor current (SRC) control shown in Fig. 6 is considered in this analysis. The results are shown in Figs.12 - 23. In Fig. 12, it is seen that the DC voltage can be controlled within the set limit by the crowbar and the DC-chopper schemes respectively. The DC chopper scheme gives a better response, due to less switching circuitry. Figs.13 and 14 show the results of the combinations of the DC chopper and the two proposed schemes (SRC and SDBR). Both schemes can limit the rotor current of the DFIG within twice its nominal value during the grid fault. However, the latter scheme can give better responses of the DC-link voltage as well as other variables like the rotor speed (Fig.15) and the terminal voltage (Fig. 16) of the DFIG.

Fig. 17 and 18 shows a comparison between the two cases with the SDBR $(0.1 \mathrm{pu})$ connected at the rotor and at the stator of the DFIG. It can be observed that better responses of the terminal voltage and rotor speed of the DFIG were achieved when the SDBR is connected at the stator during the grid fault. Figs 19-21 show the effect of the SDBR magnitude on the performances of DFIG during the grid fault. It is seen from Fig. 19 that the SDBR with $0.05 \mathrm{pu}$ resistance gives better performances for the DFIG rotor speed. Fig. 20 shows that the SDBR can improve the terminal voltage of the DFIG during the fault. It is seen from Figs. 21 that, in the cases with high SDBR resistance, there appears a peak in the responses of the active power of the DFIG, while smaller SDBR gives a better response. 
The effects of the insertion time and duration of operation of the SDBR on the performance of DFIG are shown in Figs. 22 and 23. The quicker the insertion time and the shorter the duration of operation of the SDBR are, the better responses can be obtained in the rotor speed and terminal voltage of the DFIG during the grid fault.

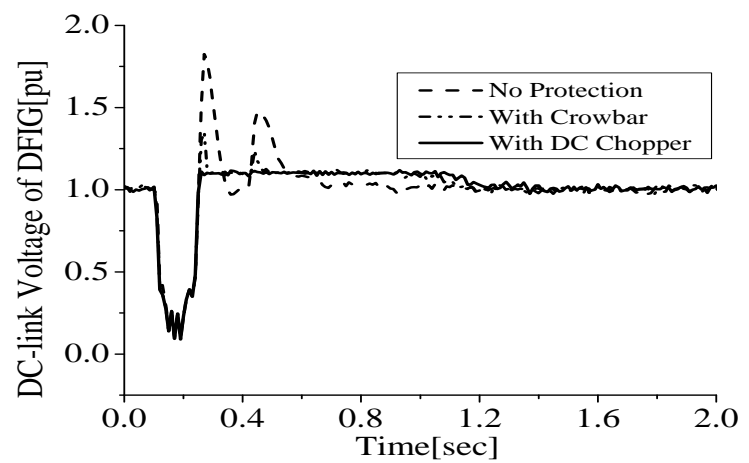

Fig. 12. DC-link voltage of DFIG (Crowbar /DC Chopper scheme)

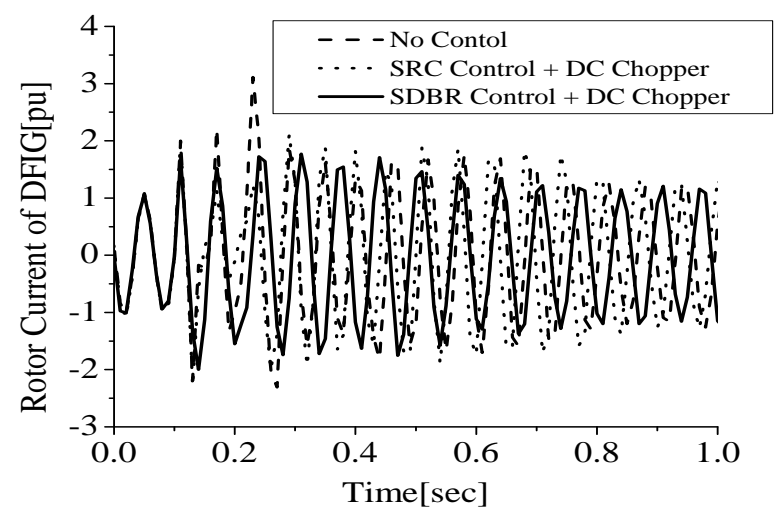

Fig. 13. Rotor current of DFIG (SRC control and SDBR scheme)

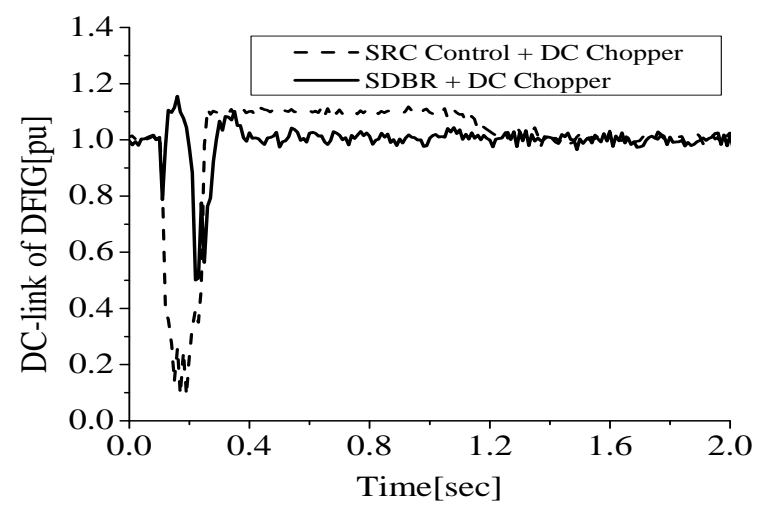

Fig. 14. DC-link voltage of DFIG (SRC control and SDBR scheme)

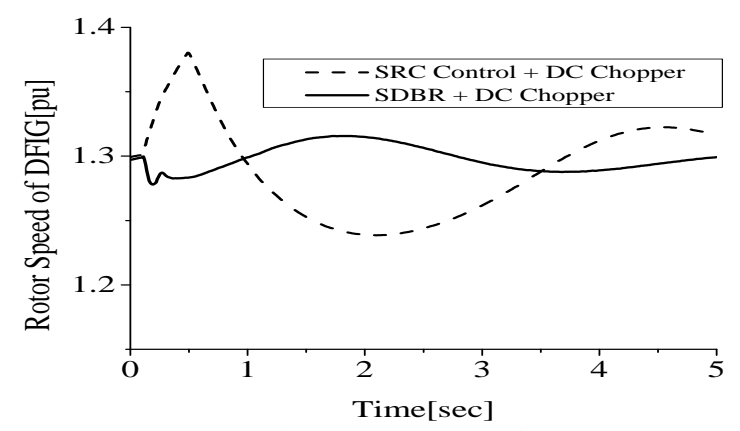

Fig. 15. Rotor speed of DFIG

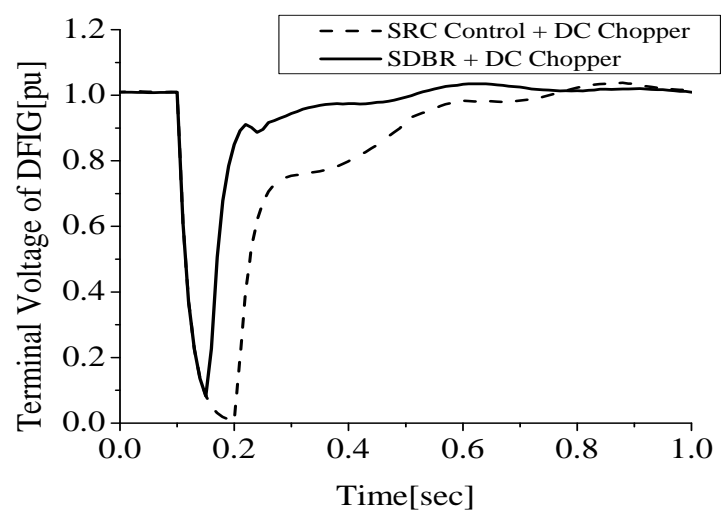

Fig. 16. Terminal voltage of DFIG

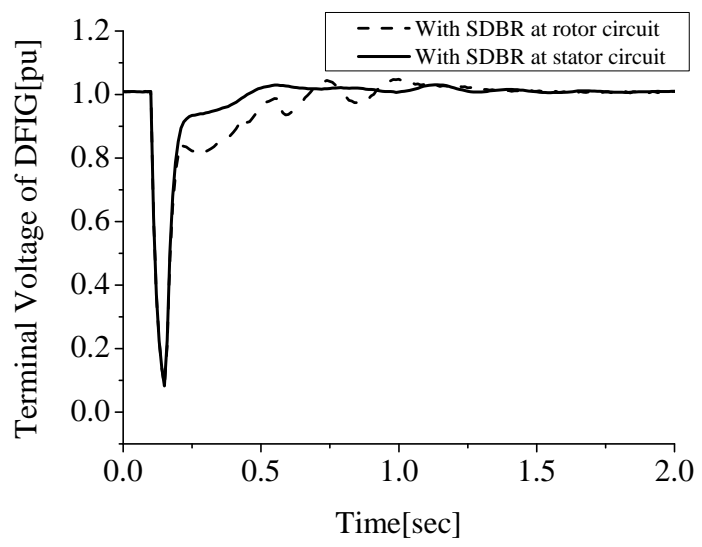

Fig. 17. Terminal voltage of DFIG with SDBR at stator and rotor

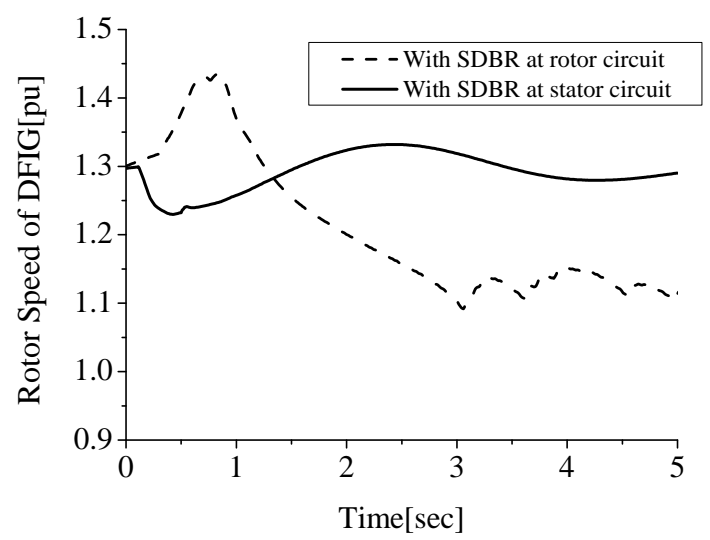

Fig. 18. Rotor speed of DFIG with SDBR at stator and rotor

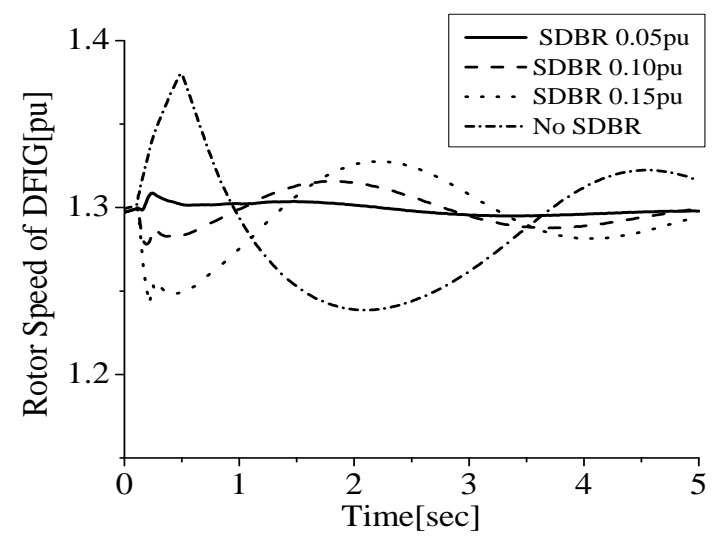

Fig. 19. Rotor speed of DFIG 


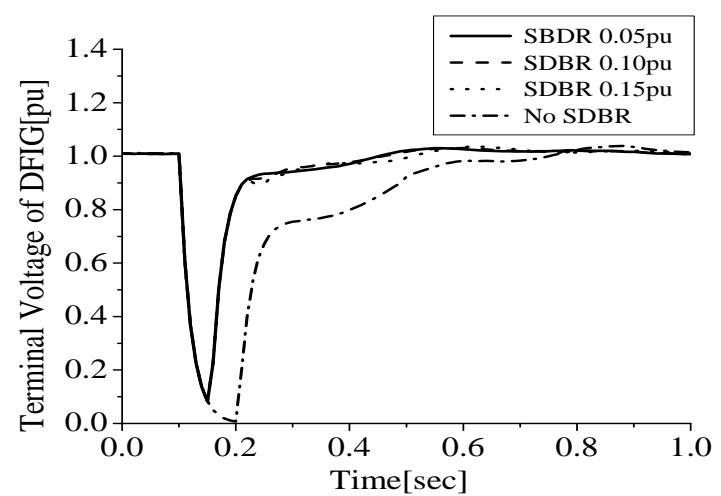

Fig. 20. Terminal voltage of DFIG

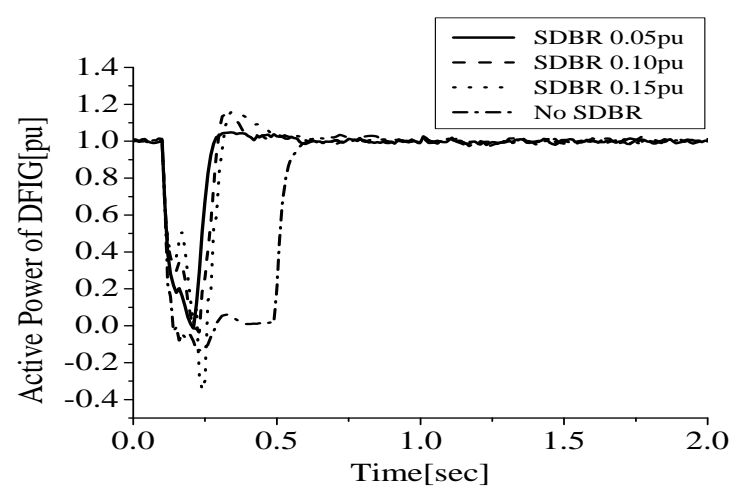

Fig. 21. Active power of DFIG

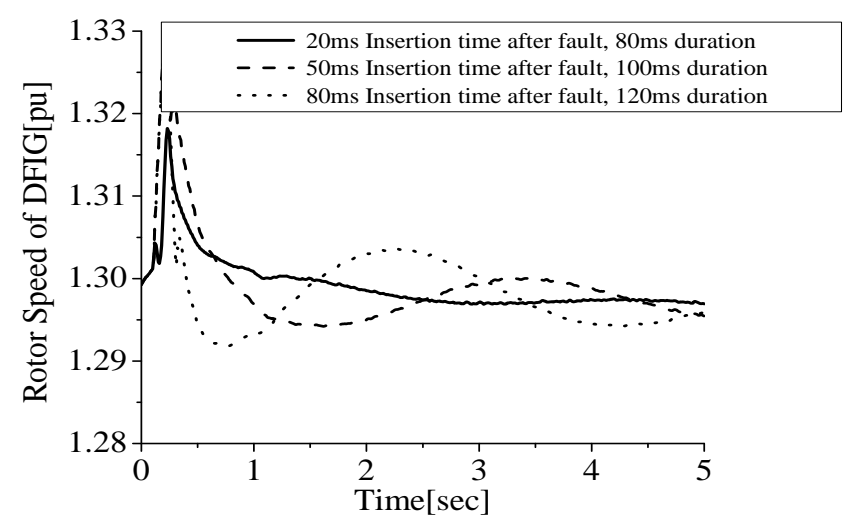

Fig. 22. Rotor speed of DFIG

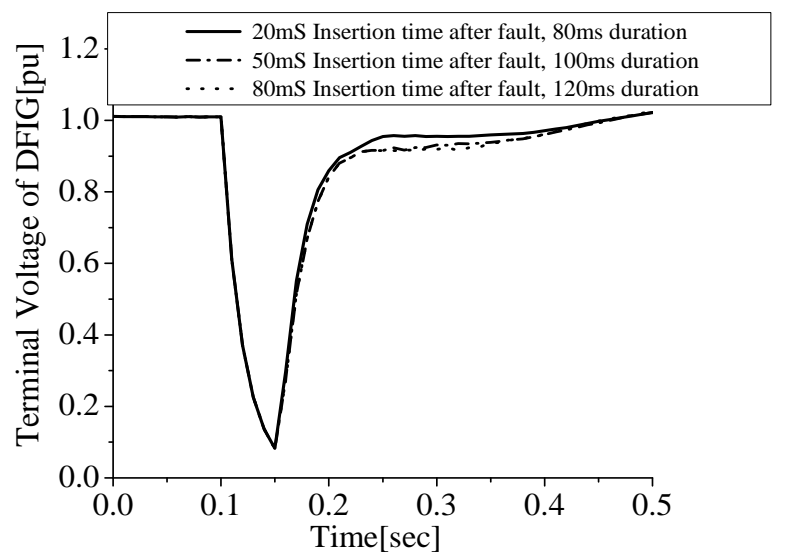

Fig. 23. Terminal voltage of DFIG

\section{B. Analysis using Multi-Machine Model:}

Simulation analyses for a $3 \mathrm{LG}$ at fault point F2 (Fig. 11) were performed in PSCAD/EMTDC for three cases. In Case-1, the DFIGs are replaced with IGs in the wind farms, while in Case-2, the DFIGs are installed with only the DC-chopper protection scheme considered. In Case-3, the SDBR control is adopted in the stator of the DFIGs. It is assumed all wind generators are operating at their rated speed. A $100 \mathrm{~ms}$ fault is considered to occur at $0.1 \mathrm{sec}$. The circuit breakers on the faulted line are opened and reclosed at $0.2 \mathrm{sec}$ and $1.0 \mathrm{sec}$ respectively. The simulation results are shown in Figs. 24-33.

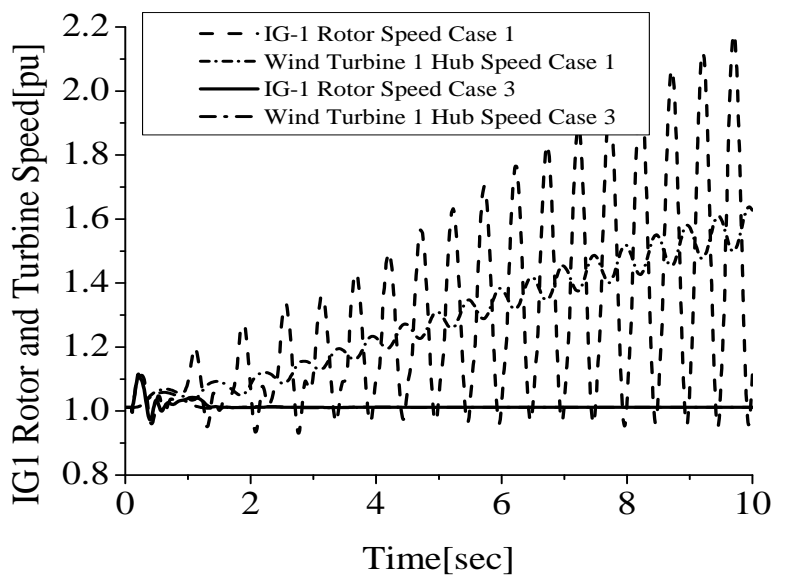

Fig 24. Rotor and turbine hub speed of IG-1

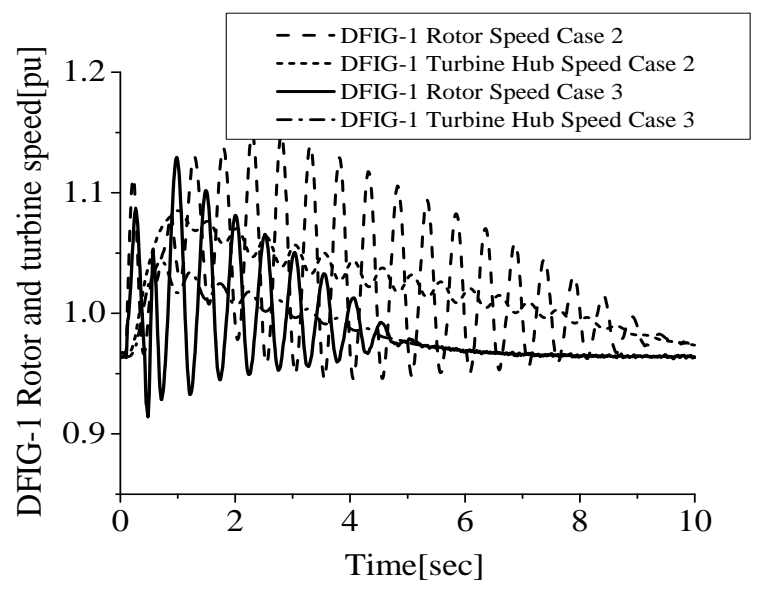

Fig 25. Rotor and turbine hub speed of DFIG-1

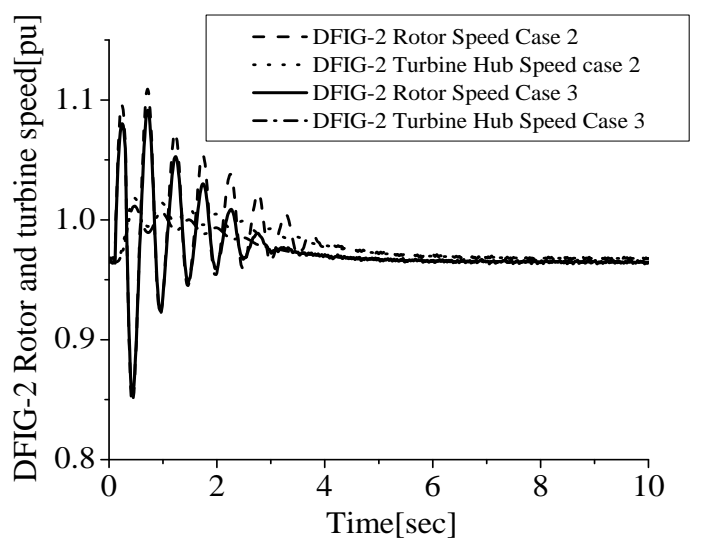

Fig.26. Rotor and turbine hub speed of DFIG-2 


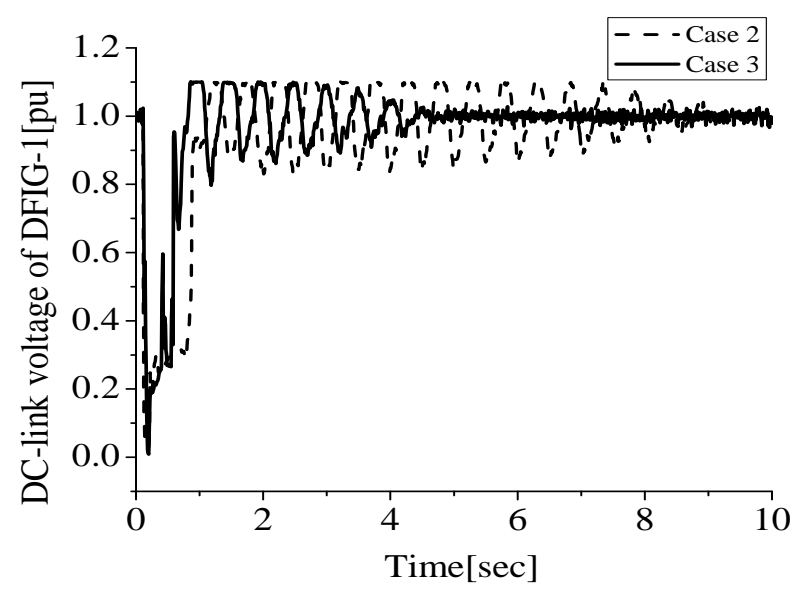

Fig.27. DC-link voltage of DFIG-1

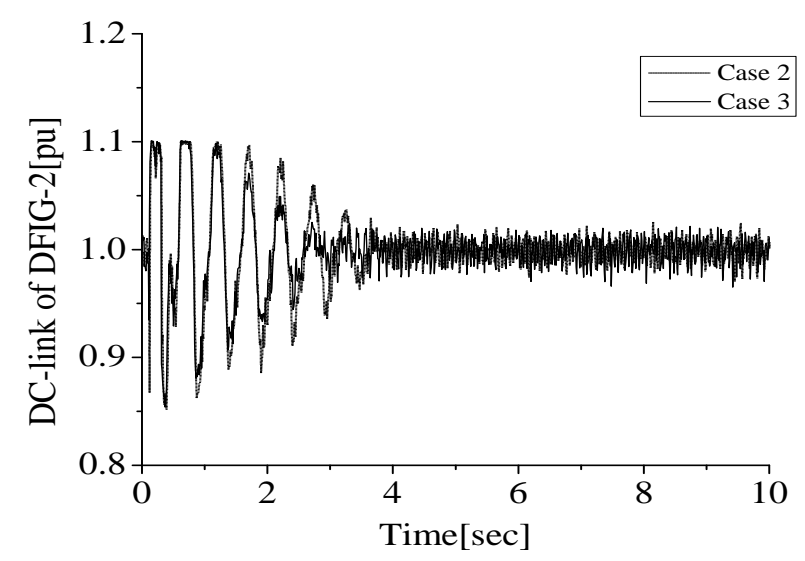

Fig. 28. DC-link voltage of DFIG-2

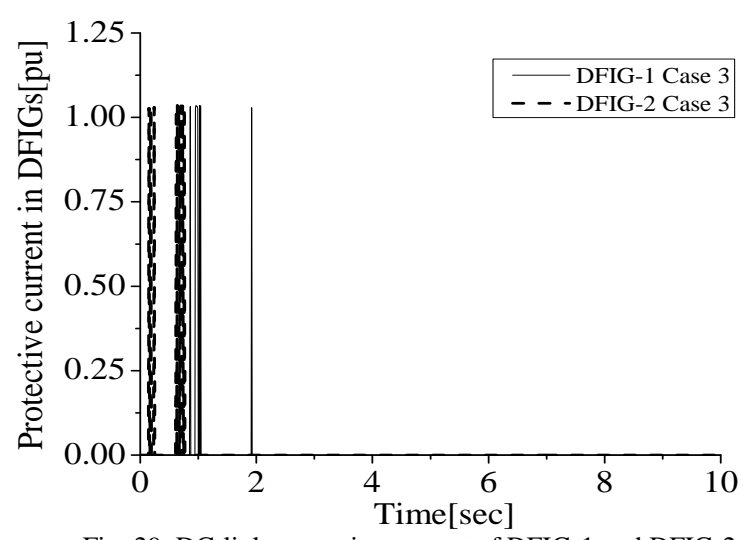

Fig. 29. DC-link protective current of DFIG-1 and DFIG-2

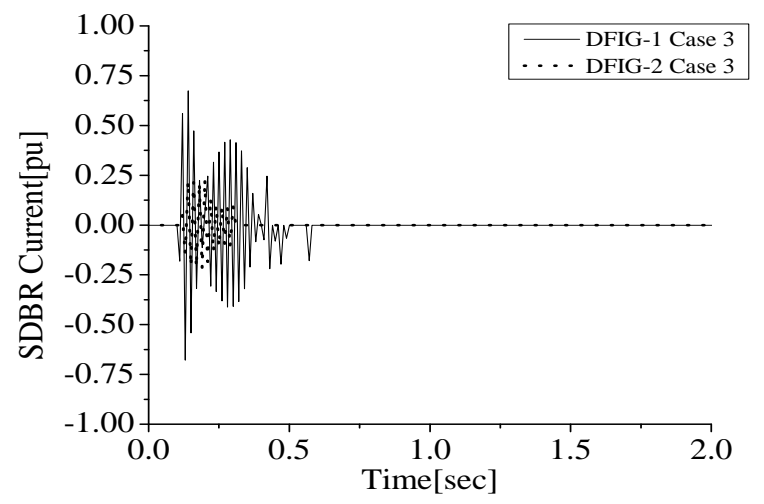

Fig.30. SDBR current of DFIG-1 and DFIG-2

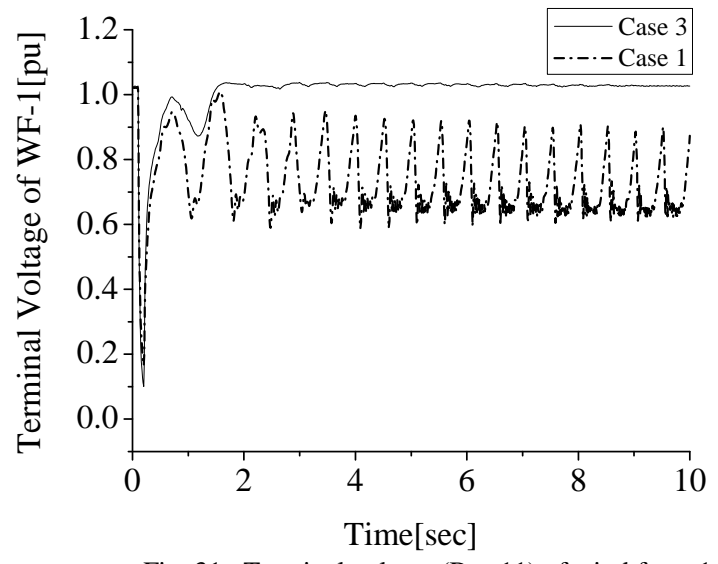

Fig. 31. Terminal voltage (Bus 11) of wind farm-1

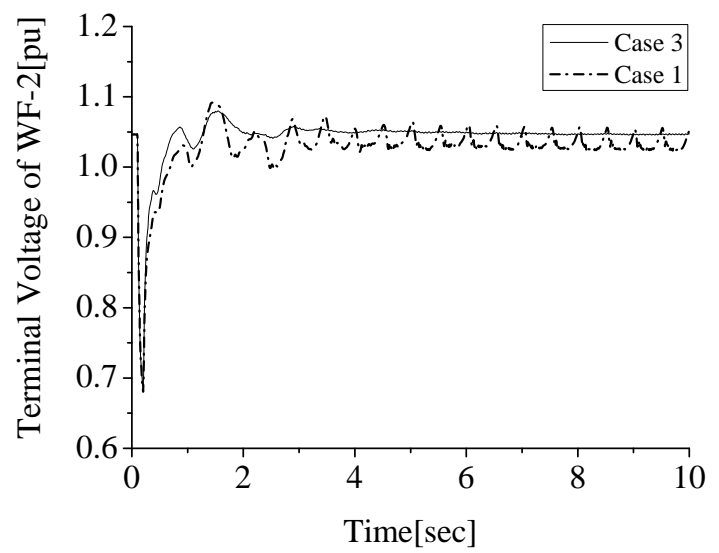

Fig. 32. Terminal voltage (Bus 18) of wind farm-2

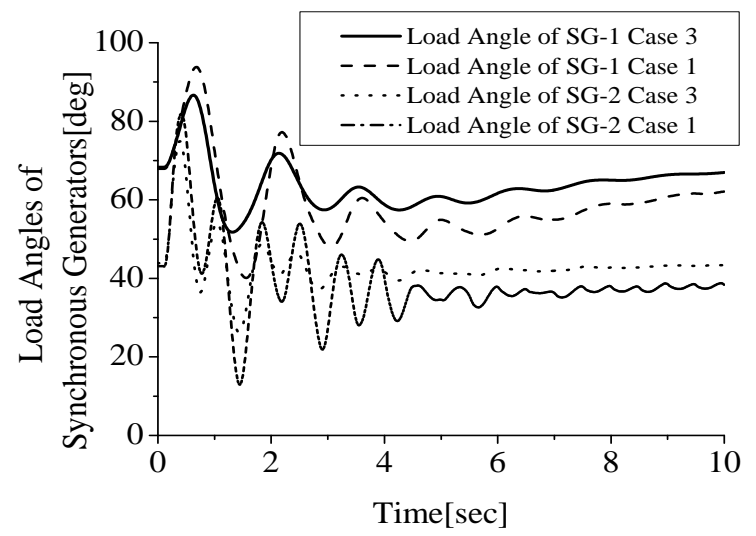

Fig. 33. Load angle of synchronous generators

Fig. 24 shows the IG1 rotor and turbine hub speeds with and without considering the DFIGs proposed control. The electromagnetic torques of the IGs drop during the grid fault, because it is proportional to the terminal voltage of the wind generator. This is demonstrating that the IGs do not have the capability of reactive power control during a grid fault. The mechanical torques of the wind turbines do not change rapidly during the short interval. As a result, the turbine hub and generator rotor accelerate due to the large difference between the mechanical and electromagnetic torques, and then, the wind generators become unstable. But if the DFIG control is considered, the necessary reactive power is supplied, and then, 
the terminal voltages of the wind farm and the electromagnetic torques of the IGs can be restored quickly, making the wind generators stable. Figs. 25 and 26 show the DFIGs rotor and turbine hub speeds responses, with and without the SDBR connected. It is seen that the SDBR can effectively improve the performance of the rotor and turbine hub speeds because it can improve the balance between the mechanical power extracted from the turbine and the generator output during and after the fault.

The DC-link voltage of the DFIGs with and without the SDBR connected is shown in Figs. 27 and 28 respectively. Figs. 29 and 30 show the currents in the DC-link protective device and the SDBR respectively. The current in the DC-link protective device only flows if Edc exceeds Edc-max, while the current in the SDBR only flows if the grid voltage $(\mathrm{Vg})$ is below 0.9 pu. Figs. 31 and 32 show the terminal voltage response at wind farm 1 and 2. When the DFIG control is not considered, the voltage drop occurs at the wind farm terminals, and it is more severe at wind farm 1 because it is more close to the fault location considered. The load angles of the synchronous generators with and without the DFIGs connected are shown in Fig. 33. When the DFIGs are connected, better performance can be achieved in the load angle responses.

\section{CONCLuSiOn}

Fault ride through (FRT) is necessary for DFIG wind power generation system. In this paper, a new control method with the DC-link chopper in combination with two protection schemes is proposed; i.e., the supplementary rotor current control in the rotor side converter (RSC) and the series dynamic braking resistor (SDBR) connected to the stator of the DFIG. Both schemes work well and are more cost effective than conventional schemes. But the second scheme is recommended, because it improves the overall system performance significantly, even though the first scheme is a bit less expensive to be realized.

Also, DFIG with the proposed scheme can augment the FRT of entire wind farms where induction generators (IGs) are present. In addition, other FACTS devices are not necessary in the proposed method.

\section{APPENDIX}

The effect of grid fault on the DFIG rotor current is analyzed as follows based on [11, 22 and 39]:

The voltage expression for phase-a is given as

$$
v_{r a}(t)=\operatorname{Re}\left[v_{r o}^{r}\right]+r_{21} \cdot i_{r a}(t)+\sigma L_{21} \frac{d i_{r a}(t)}{d t}
$$

The linear differential equation for $i_{r a}(t)$ is

$$
\frac{d i_{r a}(t)}{d t}+\frac{r_{21}}{\sigma L_{21}} i_{r a}(t)=\frac{1}{\sigma L_{21}}\left[\left(v_{r a}(t)-\operatorname{Re}\left[v_{r o}^{r}\right]\right)\right]
$$

Where $v_{r o}^{r}$ is a voltage source used to represent voltage due to the stator flux produced as given in equation (12).

$$
v_{r o}^{r}=\frac{L_{m u}}{L_{1}}\left(\frac{d}{d t}-j \omega_{r}\right) \psi_{s}
$$

$$
\sigma=1-\frac{L_{m u}^{2}}{L_{1} L_{21}}
$$

$\sigma$ is the leakage factor, while $L_{m u}, L_{1}, L_{21}, r_{21}, \omega_{r}, \psi_{s}$ are the magnetizing, stator, and rotor inductances, rotor resistance, angular rotor frequency and stator flux respectively.

Let output voltage of the converter be

$$
v_{r a}(t)=V_{r} \cos \left(s \omega_{s} t+\beta\right) \text {, where } \beta \text { is the phase-a rotor }
$$

voltage angle at the moment the fault occurs, $\omega_{s}, s \omega_{s}$, are the synchronous and slip angular frequencies respectively.

Considering a symmetrical voltage disturbance on the stator side, that is, a three phase step amplitude change from $V s$ to $(1-p) V s$ (where $p$ is the voltage dip ratio), $v_{r o}^{r}$ in (12) can exceed the maximum voltage that the rotor converter can generate, which causes the failure of current control. The voltage then becomes $v_{r o}^{r}=(1-p) V_{s} \frac{L_{m u}}{L_{1}} s e^{j s \omega_{s} t}-\frac{L_{m u}}{L_{1}}\left(\frac{1}{\tau_{s}}+j \omega_{r}\right) \frac{p V_{s}}{j \omega_{s}} e^{-t / \tau s}$

Defining time constants as

$$
\tau_{r}=\frac{\sigma L_{21}}{r_{21}}, \tau_{s}=\frac{L_{1}}{r_{1}}, \tau=\frac{\tau_{r} \tau_{s}}{\tau_{s}-\tau_{r}}
$$

Due to the small stator resistance $\left(r_{l}\right)$ of the wind generator, $\frac{1}{\tau}$ $\frac{1}{\tau}$ can be neglected in equation (14), thus

$$
v_{r o}^{r} \approx V_{s} \frac{L_{m u}}{L_{1}}\left[s(1-p) e^{j s \omega_{s} t}-(1-s) p e^{-t / \tau_{s}}\right]
$$

Considering (11) and (16), the final expression of $i_{r a}(t)$ can be solved and divided into four components

$$
i_{r a}(t)=i_{d c}+i_{v r}+i_{v r f}+i_{v r n}
$$

The four components are defined as

$i_{d c}=\left\{\begin{array}{l}i_{r a}\left(t_{0}^{-}\right)-\frac{1}{\sigma L_{21}} \frac{\tau_{r}}{1+\tau_{r}^{2}\left(s \omega_{s}\right)^{2}}\left[V_{r} \cos \beta-V_{s} \frac{L_{m u}}{L_{1}} s(1-p)\right]- \\ \frac{1}{\sigma L_{21}} V_{s} \frac{L_{m u}}{L_{1}}(1-s) p \frac{\tau}{1+\tau^{2} \omega_{r}^{2}}\end{array}\right\} e^{-\frac{t}{\tau_{r}}}$

$i_{v r}=\frac{V_{r}}{\sigma L_{21}}\left[\begin{array}{c}\frac{\tau_{r}}{1+\tau_{r}^{2} \omega_{r}^{2}} \cos \left(s \omega_{s} t+\beta\right) \\ +\frac{\tau_{r}^{2} \omega_{r}}{1+\tau_{r}^{2} \omega_{r}^{2}} \sin \left(s \omega_{s} t+\beta\right)\end{array}\right]$

$$
v r f=-\frac{1}{\sigma L_{21}} V_{s} \frac{L_{m u}}{L_{1}} s(1-p)\left[\begin{array}{c}
\frac{\tau_{r}}{1+\tau_{r}^{2}\left(s \omega_{s}\right)^{2}} \cos \left(s \omega_{s} t\right) \\
+\frac{\tau_{r}^{2} s \omega_{s}}{1+\tau_{r}^{2}\left(s \omega_{s}\right)^{2}} \sin \left(s \omega_{s} t\right)
\end{array}\right]
$$


$i_{v r n}=\frac{V_{s}}{\sigma L_{21}} \frac{L_{m u}}{L_{1}}(1-s) p\left[\frac{\tau}{1+\tau^{2} \omega_{r}^{2}} \cos \left(\omega_{r} t\right)+\frac{\tau^{2} \omega_{r}}{1+\tau^{2} \omega_{r}^{2}} \sin \left(\omega_{r} t\right)\right] e^{-t / \tau_{s}}$

Where, $s, r$, and $n$ are the stator, rotor and nominal value subscripts respectively.

From the above rotor fault current analysis, it is seen that the rotor currents of the DFIG increases abruptly during a grid fault, as described below.

From eqns. (17-21), the amplitude of each current component can be obtained by making the following approximations due to the small stator resistance:

$e^{-t / \tau_{s}} \approx 1 ; \tau \approx \tau_{r}$.

The single trigonometric function of the current components can be expressed as follow:

$i_{d c}=\left(\begin{array}{l}i_{r a}\left(t_{0}^{-}\right)-\frac{1}{\sigma L_{21}} \frac{\tau_{r}}{1+\tau_{r}^{2}\left(s \omega_{s}\right)^{2}} V_{r} \cos \beta- \\ \frac{1}{\sigma L_{21}} V_{s} \frac{L_{m u}}{L_{1}}(1-s) \frac{\tau}{1+\tau^{2} \omega_{r}^{2}}\end{array}\right) e^{-t / \tau_{r}}$

$i_{v r}=\frac{V_{r}}{\sigma L_{21}} \frac{\tau_{r}}{\sqrt{1+\tau_{r}^{2} \omega_{r}^{2}}} \sin \left(s \omega_{s} t+\beta+\varphi\right)$

$i_{v r f}=0$

$i_{v r n}=\frac{1}{\sigma L_{21}} V_{s} \frac{L_{m u}}{L_{1}}(1-s) \frac{\tau_{r}}{\sqrt{1+\tau_{r}^{2} \omega_{r}^{2}}} \sin \left(\omega_{r} t+\varphi\right)$

Where,

$\varphi=\tan ^{-1}\left(1 / \tau_{r} \omega_{r}\right)$

Thus, the amplitude of each current component at the maximum current value can be written as

$i_{r a, \max }=\left[\begin{array}{l}i_{r a}\left(t_{0}^{-}\right)-\frac{1}{\sigma L_{21}} V_{s} \frac{L_{m u}}{L_{1}}(1-s) \frac{\tau_{r}}{1+\tau_{r}^{2} \omega_{r}^{2}} \\ +\frac{V_{r}}{\sigma L_{21}} \frac{\tau_{r}}{\sqrt{1+\tau_{r}^{2} \omega_{r}^{2}}}+\frac{1}{\sigma L_{21}} V_{s} \frac{L_{m u}}{L_{1}}(1-s) \frac{\tau_{r}}{\sqrt{1+\tau_{r}^{2} \omega_{r}^{2}}}\end{array}\right]$

Since variable gain $\mathrm{K}$ which is directly proportional to the grid voltage is used to decrease the rotor currents in scheme 1, increase of the rotor current during a grid fault can be suppressed. Also, a small value of SBDR proposed in scheme 2 can help reduce the rotor fault currents during the grid fault. Hence, the proposed schemes can be used to effectively limit the rotor fault currents during a grid fault.

\section{ACKNOWLEDGMENT}

The authors would like to acknowledge Japan Gas Corporation (JGC) and The Petroleum Institute, Abu Dhabi, UAE for their support in this work.

\section{REFERENCES}

[1] J. M. Rodriguez, J. L. Fernandez, D. Beato, R. Iturbe, J. Usaola, P. Ledesma, and J. R. Wilhelmi, "Incidence on power system dynamics of high penetration of fixed speed and doubly fed wind energy systems: study of the Spanish case," IEEE Trans. Power Systems, vol. 17, no. 4, pp. 1089-1095, November, 2002.

[2] J. Morren and S. W. H. de Haan, "Ride through of wind turbines with doubly-fed induction generator during a voltage dip," IEEE Trans. Energy Conversion, vol. 20, no. 2, pp. 435-441, June, 2005.

[3] I. Erlich, J. Kretschmann, J. Fortmann, S. Mueller-Engelhardt, and H. Wrede, "Modeling of wind turbines based on doubly-fed induction generators for power system stability studies," IEEE Trans. Power System, vol. 22, no. 3, pp. 909-919, Aug. 2007.

[4] G. Pannell, D. J. Atkinson, and B. Zahawi, "Minimum-threshold crowbar for a fault ride through grid code compliant DFIG wind turbine," IEEE Trans. Energy Conver., vol. 25, no. 3, pp. 750-759, September, 2010.

[5] J. A. Suul, M. Molinas, and T. Undeland, "STATCOM-based indirect torque control of induction machines during voltage recovery after grid faults," IEEE Trans. Power Electronics, vol. 25, no. 5, pp. 1240-1250, 2010.

[6] J. Yu, X. Duan, Y. Tang, and P. Yuan, "Control scheme studies of voltage source type superconducting magnetic energy storage (SMES) under asymmetrical voltage, "IEEE Trans. Applied Superconductivity," vol. 12, no. 1, pp. 750-753, 2002.

[7] S. M. Muyeen, R. Takahashi, M. H. Ali, T. Murata, and J. Tamura, "Transient stability augmentation of power of power systems including wind farms using ECS," IEEE Trans. Power Systems, vol. 23, no. 3, pp. 1179-1187, 2008.

[8] J. Morren and S. W. H. de Haan, "Short-circuit current of wind turbines with doubly fed induction generator," IEEE Trans. Energy Convers., vol. 22, no. 1, pp. 174-180, March, 2007.

[9] P. S. Flannery and G. Venkataramann, "A fault tolerant doubly fed induction generator wind turbine using parallel grid side rectifier and series grid side converter," IEEE Trans. Power Electronics, vol. 23, no. 3, pp. 1126-1135, May, 2008.

[10] M. S. Vicatos and J. A. Tegopoulous, "Transient state analysis of a doubly fed induction generator under three phase short circuit," IEEE Trans. Energy Convers., vol. 6, no. 1, pp. 62-68, March 1991.

[11] J. Lopez, E. Gubia, P. Sanchis, X. Roboam, and L. Marroyo, "Wind turbines based on doubly fed induction generator under asymmetrical voltage dips, " IEEE Trans. Energy Convers., vol. 23, no. 1, pp. 321-330, March, 2008.

[12] M. Rodriguez, G. Abad, I. Sarasola, and A. Gilabert, "Crowbar control algorithms for doubly fed induction generator during voltage dips," Presented at the $11^{\text {th }}$ Eur. Conf. Power Electronics Application, Dresden, Germany, September, 11-14, 2005.

[13] J. Yao, H. Li., Y. Liao, and Z. Chen, "An improved control strategy of limiting the DC-link voltage fluctuation for a doubly fed induction wind generator," IEEE Trans. Power Electronics, vol. 23, no. 3, pp. 1205-1213, May, 2008.

[14] R. Takahashi, J. Tamura, M. Futami, M. Kimura and K. Idle, "A new control method for wind energy conversion system using doubly fed synchronous generators," IEEJ Trans. Power and Energy, vol. 126, no. 2, pp. 225-235, 2006.

[15] M. B. C. Salles, J. R. Cardoso, A. P. Grilo, C. Rahmann, and K. Hameyer, "Control strategies of doubly fed induction generators to support grid voltage," In the proceedings of IEEE International Electric Machines and Drives Conference - IEMDC 2009, Miami, FL, USA, May, 2009.

[16] K. E. Okedu, S. M. Muyeen, R. Takahashi, and J. Tamura, "Comparative study between two protection schemes for DFIG-based wind generator," International Conference on Electrical Machines and Systems (ICEMS), Seoul, South Korea, 2010.

[17] H. Awad, J. Svensson, and M. Bollen, "Mitigation of unbalanced voltage dips using static series compensator," IEEE Trans. Power Electronics, vol. 19, pp. 837-846, May, 2004.

[18] R. G. de Almeida, J. A. Lopez, J. A. L. Barreiros, "Improving power system dynamics behavior through doubly fed induction machines 
controlled by static converter using fuzzy control," IEEE Trans. Power System, vol. 19, no. 4, pp. 1942-1950, November, 2004.

[19] A. O. Ibrahim, T. H. Nguyen, D. Lee, and S. Kim, "Ride through strategy for DFIG wind turbine systems using dynamic voltage restorers," Proceedings IEEE-ECCE (Energy Conversion Congress and Exposition), California, USA, 2009

[20] Q. Wei, G. K. Venayagamorthy, and R. G. Harley, "Real-time implementation of a STATCOM on a wind farm equipped with doubly fed induction generators, "IEEE Trans. Ind. Appl., vol. 45, no.1, pp. 98-107, January, 2009.

[21] A. Causebrook, D. J. Atkinson, and A. G. Jack, "Fault ride through of large wind farms using series dynamic braking resistors," IEEE Trans. Power Systems, vol. 22, no. 3, pp. 966-975, March, 2007.

[22] J. Yang, E. Fletcher, and J. O'Reilly,'A series dynamic resistor based converter protection schemes for doubly fed induction generator during various fault conditions," IEEE Tran. Energy Convers. Vol. 25, no. 2, pp. 422-432, June, 2010

[23] W. Park, B. C. Sung, and J. W. Park, "The effect of SFCL on electric power grid with wind turbine generation system," IEEE Trans. Applied Superconductivity, vol. 20, no. 3, pp. 1177-1181, June, 2010.

[24] X. Yan, G. Venkataramanan, and Y. Wang, "Grid fault tolerant operation of DFIG wind turbine generator using a passive resistance network," Proceedings IEEE-ECCE (Energy Conversion Congress and Exposition), California, USA, 2009

[25] A. Petersson, S. Lundberg, and T. Thiringer, "A DFIG wind turbine ride through system influence on energy production," Wind Energy Journal, vol. 8, pp. 251-263, 2005.

[26] "PSCAD/EMTDC Manual", Manitoba HVDC research center, 1994.

[27] T. Sun, Z. Chen, and F. Blaabjerg, "Transient stability of DFIG wind turbines at an external short circuit fault," Wind Energy Journal, vol. 8, pp. 345-360, 2005 .

[28] O. Wasynczuk, D. T. Man, and J. P. Sullivan, "Dynamic behavior of a class of wind turbine generator during random wind fluctuations," IEEE Trans. Power Apparatus and Systems, PAS, vol. 100, no. 6, pp. 2837-2845, 1981.

[29] M. B. C. Salles, K. Hameyer, J. R. Cardoso, A. P. Grilo, and C. Rahmann, "Crowbar system in doubly fed induction wind generators," Energies Article Journal, ISSN 1996-1073, vol. 3, pp. 738-753, 2010.

[30] M. Wang-Hansen, "Wind power dynamic behavior-Real case study on Linderodsasen wind farm," Dissertation, Department of Energy/Envir. Division of Elect. Power Engineering, Chalmers Univ., Sweden, 2008.

[31] K. E. Okedu, S. M. Muyeen, R. Takahashi, and J. Tamura, "Use of Supplementary Rotor Current Control in DFIG to Augment Fault Ride Through of Wind Farm as per Grid Requirement", Paper accepted for the $37^{\text {th }}$ Annual Conference of IEEE Industrial Electronics Society (IECON 2011), Melbourne, Australia, Nov. 7-10, 2011, paper no. MD-005797.

[32] K.E. Okedu, S. M. Muyeen, Rion Takahashi and Junji Tamura, "Protection Schemes for DFIG Considering Rotor Current and DC-link Voltage", Paper accepted for the $24^{\text {th }}$ ICEMS (International Conference on Electrical Machines and System), Beijing, China, August 2011, Paper no. 025.

[33] K.E. Okedu, S. M. Muyeen, Rion Takahashi and Junji Tamura, "Improvement of Fault Ride Through Capability of Wind Farm using DFIG Considering SDBR", Paper accepted for the $14^{\text {th }}$ European Conference of Power Electronics EPE, Birmingham, United Kingdom, August, 2011, Paper no. 306

[34] K.E. Okedu, S. M. Muyeen, Rion Takahashi and Junji Tamura, "Application of SDBR with DFIG to Augment Wind Farm Fault Ride Through", Paper accepted for the $24^{\text {th }}$ IEEE-ICEMS (International Conference on Electrical Machines and Systems), Beijing, China, August 2011, Paper no. 026.

[35] K. E. Okedu, S. M. Muyeen, R. Takahashi, and J. Tamura, "Stabilization of wind farms by DFIG-based variable speed wind generators," International Conference on Electrical Machines and Systems (ICEMS), Seoul, South Korea, 2010.

[36] Working Group on Prime Mover and Energy Supply Models for System Dynamic Performance Studies, "Hydraulic turbine and turbine control models for fossil fueled steam units on power system studies," IEEE Trans. Power System, vol. 6, no. 2, pp. 753-761, 1991.

[37] Working Group on Prime Mover and Energy Supply Models for System Dynamic Performance Studies, "Hydraulic turbines and turbine control models for system dynamic studies," IEEE Trans. Power System, vol. 7, no. 1 , pp. 167-179.

[38] "IEEE Recommended Practice for Excitation System Models for Power System Stability Studies," IEEE Std, 1992; 421.5
[39] J. Lopez, P. Sanchis, X. Roboam, and L. Marroyo, "Dynamic behavior of the doubly fed induction generator during three phase voltage dips," IEEE Trans. Energy Convers., vol. 22, no. 3, pp. 709-717, Sept. 2007.

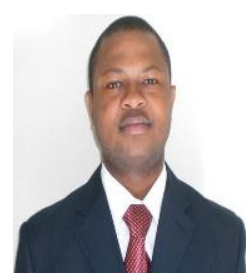

Kenneth E. Okedu (S'09) is currently a Ph.D. student in the department of Electrical and Electronic Engineering, Kitami Institute of Technology, Hokkaido, Japan. He received his B.Sc. and M. Eng. degrees in Electrical and Electronic Engineering from the University of Port Harcourt, Nigeria in 2003 and 2006 respectively. His research interests include the stabilization of wind farm with doubly fed induction wind generator variable speed wind turbine, and power system stability analysis.

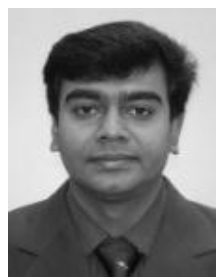

S. M. Muyeen (M' 08) received his B.Sc. Eng. degree from Rajshahi University of Engineering and Technology (RUET), Bangladesh, formerly known as Rajshahi Institute of Technology, in 2000, and M. Sc. Eng. and Dr. Eng. degrees from Kitami Institute of Technology, Japan, in 2005 and 2008 respectively, all in Electrical and Electronic Engineering. After completing his Ph.D. program he worked as a Postdoctoral Research Fellow under the versatile banner of Japan Society for the Promotion of Science (JSPS) from 2008-2010 at the Kitami Institute of Technology, Japan. Presently he is working as Assistant Professor in Electrical Engineering department at the Petroleum Institute, UAE. His research interests are power system stability and control, electrical machine, FACTS, energy storage system (ESS), renewable energy, and HVDC system.

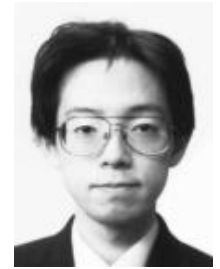

Rion Takahashi (M' 07)) received the B.Sc. Eng. and Dr. Eng. degrees from Kitami Institute of Technology, Japan, in 1998 and 2006 respectively, all in Electrical and Electronic Engineering. Now he is working as Associate Professor in Department of Electrical and Electronic Engineering, Kitami Institute of Technology. His major research interests include analysis of power system transient, FACTS and wind energy conversion system.

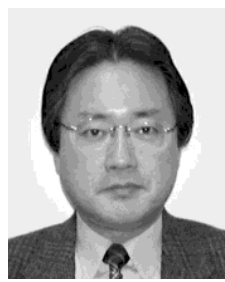

Junji Tamura (M'87-SM'92) received his B. Sc. Eng. degree from Muroran Institute of Technology, Japan, in 1979 and M.Sc. Eng. and Dr. Eng. degrees from Hokkaido University, Japan, in 1981 and 1984 respectively, all in Electrical Engineering. He became a lecturer in 1984, an Associate Professor in 1986, and a Professor in 1996 at the Kitami Institute of Technology, Japan. Currently he is a Vice President of the Kitami Institute of Technology. 